Brief papers

\title{
Two sibs who are double heterozygotes for achondroplasia and pseudoachondroplastic dysplasia
}

\author{
C G Woods, J G Rogers, V Mayne
}

\begin{abstract}
We report a family in which two sibs have both achondroplasia and pseudoachondroplastic dysplasia. The mother has achondroplasia and the father has pseudoachondroplastic dysplasia, which he had inherited from his father. Both children appeared typical of achondroplasia at birth. By $1 \frac{1}{2}$ years they had developed a fixed lumbar kyphosis with gibbus and had additional $x$ ray changes unusual for just achondroplasia and suggestive of pseudoachondroplastic dysplasia. Subsequently both children have shown characteristic features of both conditions and have grown less well than expected for achondroplasia. Radiographs show the striking synergistic effects of the two conditions. MRI in both sibs confirmed brain stem compression at the foramen magnum. This may be an important complication and should be actively sought in any double heterozygote.
\end{abstract}

(f Med Genet 1994;31:565-569)

Achondroplasia and pseudoachondroplastic dysplasia are separate and specific autosomal dominant causes of disproportional dwarfism. We describe the double heterozygote effects of these conditions in two sibs born of an achondroplastic mother and a father with pseudoachondroplastic dysplasia.

Victorian Clinical Genetics Service, The Murdoch Institute, Royal Children's Hospital, Flemington Road, Parkville, Melbourne, Victoria 3052, Australia C G Woods J G Rogers

Department of Radiology, Royal Children's Hospital Flemington Road, Parkville, Melbourne, Victoria 3052, Australia V Mayne

Correspondence to Dr Woods.

Received 17 November 1993 Revised version accepted for publication 3 March 1994

\section{Case reports}

The pedigree is shown in fig 1 . The father of the children, III.1, has pseudoachondroplastic dysplasia inherited from his father, II.1. His grandfather was also affected. The mother of the children, III.2, has achondroplasia as the result of a new mutation.

The father, III.1, has windswept deformity of his legs but otherwise both he and the mother, III.2, are in good health and have no significant orthopaedic or neurological symptoms. Both have been known to our department since early childhood and their diagnoses are secure based on longitudinal clinical and radiological observation. This couple were counselled after marriage of the 1 in 4 chance of a normal child, 1 in 4 chance of a compound

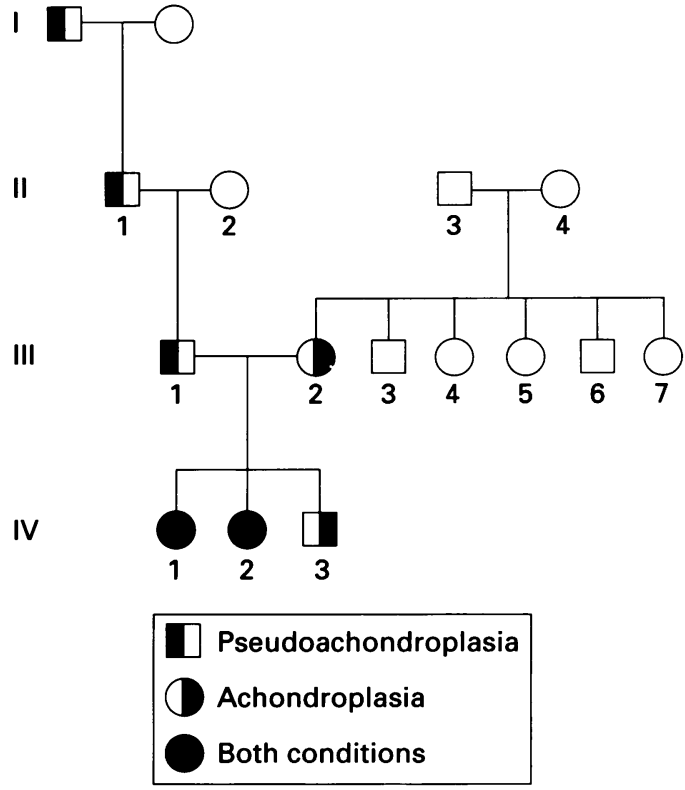

Figure 1 Family pedigree showing birth order and those with skeletal dysplasias.

heterozygote, and 1 in 4 chance of achondroplasia alone and 1 in 4 chance of pseudoachondroplastic dysplasia alone.

The couple have three children, two females, IV.1 and IV.2, and a male, IV.3. The children IV. 2 and IV. 3 are shown in fig 2.

CASE 1

The first child, IV.1, was born after an uneventful pregnancy and delivered by caesarean section. Achondroplasia was apparent at birth. She was very short $(40 \mathrm{~cm},<3$ rd centile), with mesomelic limb shortening, a large head (90th centile), spatulate hands with inability to approximate the fingers in extension, hypotonia, and marked hyperextensibility of the wrists and ankles. She had typical radiographic findings of achondroplasia in the first year of life (not shown), lucent zones in the proximal femora, narrowing of the interpedicular distances in the lower lumbar spine, and short lumbar pedicles. The iliac wings were short and square and the acetabular roof was horizontal with narrowing of the greater sciatic notch. At 1 year, kyphosis of the thoracolumbar spine on sitting was noted and was not totally corrected when lying. Spinal bracing with a body jacket 

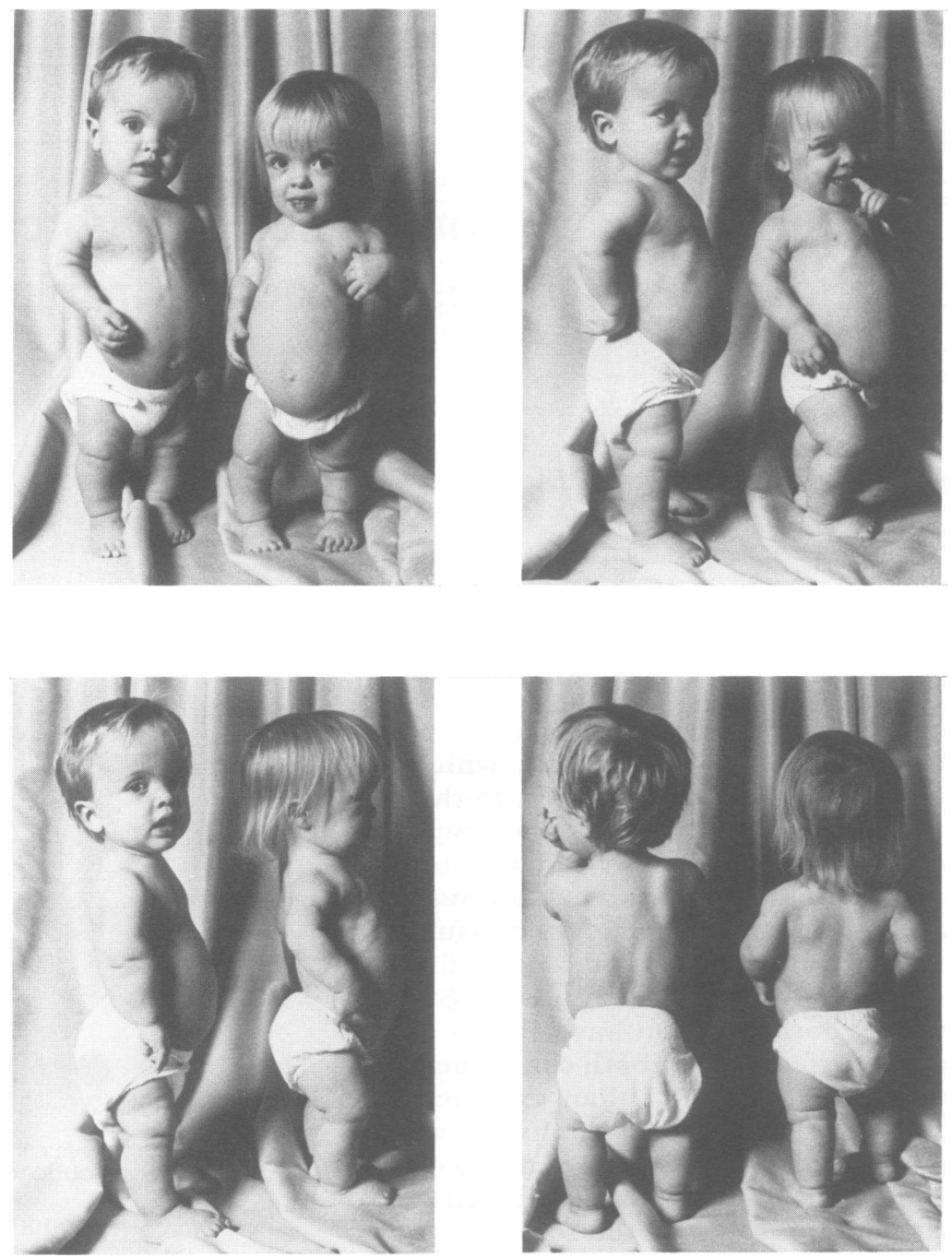

Figure 2 Four views of female III.2 on the right and her brother III.3 on the left

III.2 aged $3 \frac{1}{2}$ years has achondroplasia and pseudoachondroplastic dysplasia, and III.3 aged 18 months has achondroplasia. Note the typical facies, body proportions, and stance of achondroplasia in both, and that III.2 is shorter than her younger brother III.3. His ventriculoperitoneal shunt is visible substernally.

for six months failed to prevent progressive kyphosis.

From 9 months of age, $x$ rays showed progressive anterior wedging of vertebrae particularly at the apex of the kyphosis, typical of pseudoachondroplastic dysplasia (fig 3B, C, D, and $\mathrm{E}$ ). The gibbus became fixed by $1 \frac{1}{2}$ years. By 5 years severe radiographic changes characteristic of pseudoachondroplastic dysplasia were apparent as well as those expected for achondroplasia. Wedging, anterior tongue-like protrusions, and kyphoscoliosis were present as was delayed capital femoral epiphysis ossification (fig 3A). The marked epiphyseal changes of pseudoachondroplastic dysplasia and combined shortening of long bones seen in both conditions are shown in fig $3 \mathrm{~F}-\mathrm{K}$.

Her development and health have been normal apart from the acquisition of gross motor skills. She had minor dilatation of the cerebral ventricles suspected clinically and confirmed by ultrasonography which did not progress after 1 year of age. From the age of 2 years her body shape, gait, and posture has become typical of pseudoachondroplastic dysplasia. Her growth has been slower than expected in achondroplasia. ${ }^{1}$ From the age of 3 years she had instability of the knees and ankles, a waddling gait, slight bowing of the knees, and found it difficult to walk. Her wrists are also lax. Recently her exercise tolerance has diminished although she has no respiratory or cardiac symptoms nor discomfort on walking. Brain stem or spinal cord compression was suspected and an MRI scan performed (fig $3 \mathrm{~L}, \mathrm{M}, \mathrm{N}$ ). This confirmed compression of the brain stem at the level of the foramen magnum with posterior flattening, but no obvious brain stem damage. A narrowed lower spinal canal beneath the corda aquina was also seen. A decompression of the foramen magnum and posterior cranial fossa was performed. The bone in the region of the foramen magnum was deeply shelved and difficult to remove. Postoperatively her gait is steadier, but she still falls and is clearly weak in her lower limbs.

CASE 2

The second child, IV.2, was born after an uneventful pregnancy and delivered by caesarean section. A clinical diagnosis of achondroplasia was made at birth. Her head circumference at birth was $28 \mathrm{~cm}$ (on the 25th centile for 

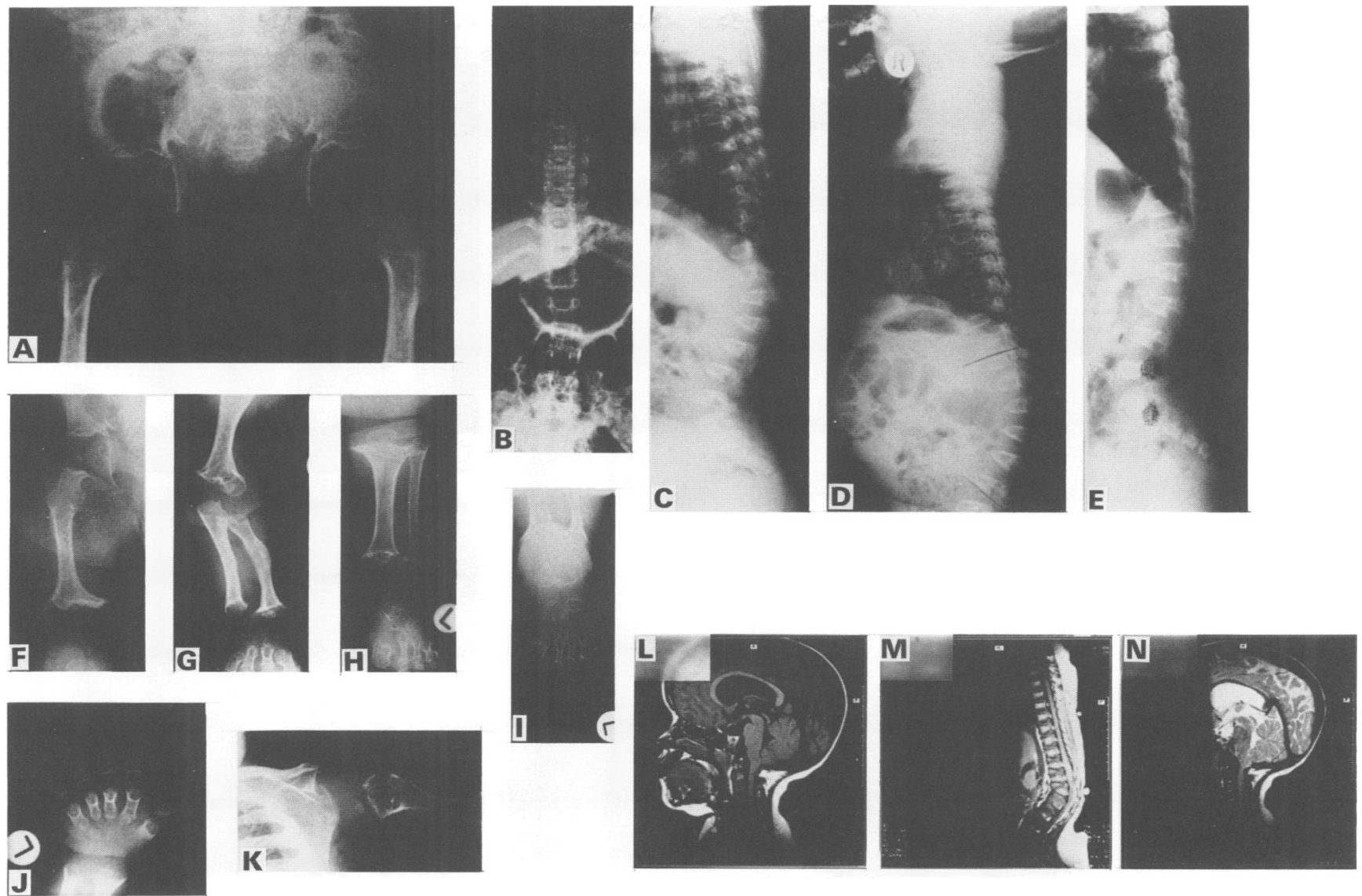

Figure $3 X$ rays and MRI scans of female III.1 at 5 years unless otherwise stated. (A) AP pelvis, (B) AP spine, (C) lateral spine at 21 months, $(D)$ lateral spine at 1 year, (E) lateral spine at 9 months, (F) right femur at 5 years, (G) AP left forearm, (H) left lower leg, (I) left foot, (予) left hand, (K) $A P$ left shoulder, (L) $T 1$ weighted $M R I$ of brain showing brain stem compression at the foramen magnum, (M) T1 weighted MRI of spinal cord showing gibbus and mild lumbar stenosis, (N) T2 weighted MRI of brain showing stem compression at the foramen magnum but with no features of brain stem damage.

Figure $4 X$ rays of female III.2. ( $A$ ) Lateral spine at 17 months showing kyphosis and anterior wedging of lumbar vertebrae, $(B)$ lateral spine at 3 years showing kyphosis, lumbar gibbus, and more marked anterior wedging of lumbar vertebrae, (C) $A P$ spine and pelvis at 3 years showing lumbar platyspondyly and interpeduncular narrowing of lumbar vertebrae. 

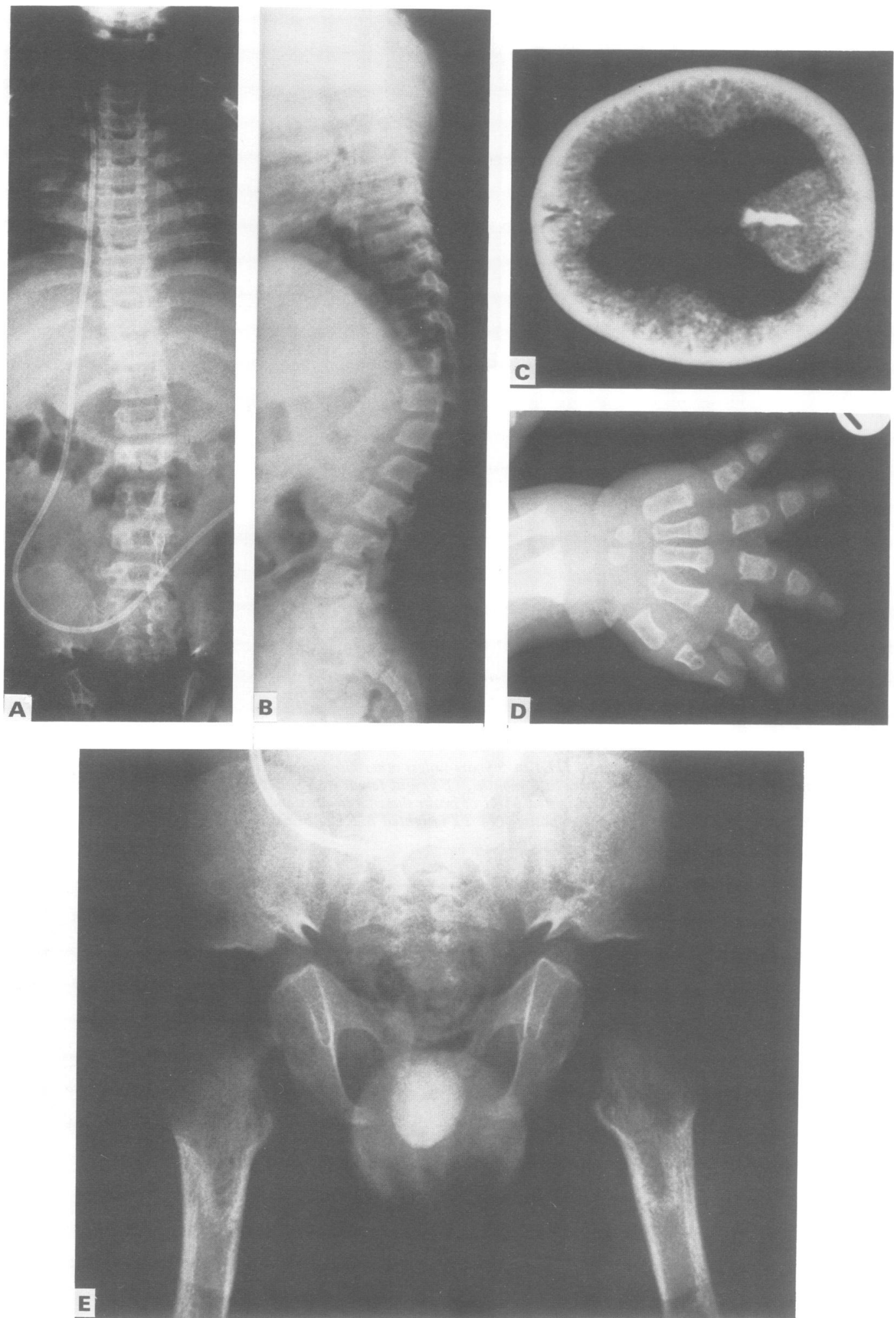

Figure $5 X$ rays of male III.3. (A) AP spine at 22 months, (B) lateral spine at 15 months, (C) CT scan of brain at 11 months, (D) left hand at 22 months, (E) AP pelvis at 22 months.

achondroplasia ${ }^{2}$ ), by 3 months it was on the 50 th centile, and by 18 months it was on the 75th centile. Thereafter growth followed the 75th centile. Ultrasound scans of her head during this period showed mild dilatation of the lateral and third ventricles. By 1 year she had developed a fixed lumbar kyphosis. Radiographs taken at 17 months and 3 years of age confirmed that she too had pseudoachondroplastic dysplasia as well as achondroplasia (fig
4). As with her sister, motor milestones were delayed, but otherwise developmental progress has been normal. She has not had any ENT problems, joint stiffness, swelling, or pain. She has grown less well than expected for achondroplasia after the first year of life. On examination at $3 \frac{1}{2}$ years she had typical findings of achondroplasia, a fixed lumbar gibbus, a waddling gait, and marked laxity of her wrists, knees, and ankles. Her strength and reflexes 
were normal but tone was reduced. An MRI scan of the neuraxis showed stenosis of the craniocervical junction with indentation of structures by the posterior margin of the foramen magnum. She developed signs of progressive urinary retention. She had the same operation as her older sib and with identical findings of a deeply shelved foramen magnum. Postoperatively the urinary retention has resolved and her mother feels her gait has improved.

She is shown with her brother, IV.3, who has achondroplasia in fig 2.

CASE 3

The third child was a boy, IV.3. At birth he had achondroplasia with characteristic changes confirmed radiologically. Rapid head growth was confirmed by 9 months. Ultrasound scanning at 6 months showed moderate dilatation of the lateral ventricles and to a lesser extent the third ventricle. A CT scan confirmed hydrocephalus and a ventriculoperitoneal shunt was inserted (fig $5 \mathrm{C}$ ). Lateral spine $x$ rays taken at 15 and 22 months (fig $5 \mathrm{~A}$ and $\mathrm{B}$ ) were clearly different from those of his two sisters, showing only the kyphosis and interpeduncular narrowing of achondroplasia. He has no clinical or other additional radiological findings other than those expected for achondroplasia (fig $5 \mathrm{D}$ and $\mathrm{E}$ ).

\section{Discussion}

At birth the two females, IV.1 and IV.2, appeared to have achondroplasia. The development of a fixed lumbar gibbus, unusual spinal changes, increasing joint laxity of the hands, and characteristic gait and hand posture made the presence of the pseudoachondroplastic dysplasia apparent. The two females now have typical clinical and radiological findings of achondroplasia $^{3}$ and pseudoachondroplastic dysplasia, ${ }^{4}$ whereas the brother, IV.3, has only the findings of achondroplasia.

With the occurrence of both conditions in our patients, we note that the following features suggest synergy of the primary skeletal defects. The development of anterior tongues in vertebral bodies in pseudoachondroplastic dysplasia is unusual before the age of 2 years, but was seen earlier in these two females. Both children are unusually short and growing poorly. Both children have required posterior fossa surgery for cord compression at the level of the foramen magnum. This is a known complication of achondroplasia, ${ }^{5}$ but its occurrence in both III.1 and III.2 may indicate that it is a common complication of achondroplasia/pseudoachondroplastic dysplasia double heterozygotes. In view of this experience we feel that an MRI scan should be performed at the earliest opportunity as the cord damage appears to be progressive. If compression is confirmed early, surgery may lead to a reduction in neurological deficit.

A previously described child with achondroplasia and pseudoachondroplastic dysplasia had similar clinical and $x$ ray findings to those described here. ${ }^{6}$ In contrast to our cases who had foramen magnum compression, only a narrowed lumbar spinal canal was found on MRI imaging.

The interaction of the two conditions in these children seems relatively mild in comparison with homozygous achondroplasia which causes a more severe phenyotype. ${ }^{7}$

The appearance of the $x$ rays of the spine and the demonstrable narrowing of the canal on MRI scan raises questions about the future problems and their management for these sibs.

We gratefully acknowledge the expert assistance of Dr Ethna Phelan and Professor David Danks.

1 Horton WA. Standard growth curves for achondroplasia. $\mathcal{f}$ Pediatr 1978;93:435-8.

2 Dawson DV. Confidence bands for the growth of head circumference in achondroplastic children during the first year of life. Am $\mathcal{F}$ Med Genet 1980;7:529-32.

3 Spranger JW, Langer LO, Wiedemann HR. Bone dysplasias: an atlas of constitutional disorders of skeletal development. Philadelphia: Saunders, 1974:55-61.

4 Hall JG. Pseudoachondroplasia. Birth Defects 1975;11(6): 187-202.

5 Hecht JT. Long term neurological sequelae in achondroplasia. Eur $\mathcal{F}$ Pediatr 1984;143:58-60.

6 Langer LO, Schaefer GB, Wadsworth DT. Patient with double heterozygosity for achondroplasia and pseudodouble heterozygosity for achondroplasia and
achondroplasia. Am $\mathcal{F}$ Med Genet 1993;47:772-81.

7 Pauli RM, Conroy MM, Langer LO, et al. Homozygous achondroplasia with survival beyond infancy. Am $\mathcal{f}$ Med achondroplasia with su
Genet 1983;16:459-73. 